\title{
Marrying computers with biology
}

An interesting symposium last month suggests that computation and molecular biology, already interdependent, are about to become inextricably linked.

Waterville Valley. Ski resorts like this can still be alive in the summer, as Aspen in Colorado has proved. This hilly (rather than mountainous) patch of central New Hampshire is a poor man's Aspen in the winter: the quality of the snow leaves experienced skiers scornful (and, until last winter, there had not been much of it for three seasons). But this summer the condos (short for 'condominiums') have been brought to life not just by trade conventions but by the Third International Symposium and Workshop on Macromolecules, Genes and Computers.

What happens when you throw together more than a hundred each of molecular biologists and computer scientists for the best part of a week? That, of course, is more than an experiment in sociology: these days, the two groups have tangible things to say to each other. That they would seems to have been why Professor Temple F. Smith of Boston University organized the first of these events six years ago. In the general opinion of those at this year's meeting, he ought to begin now to organize the next occasion in three years, or even sooner. Most of those present seem to have been stimulated by the this year's proceedings (17-22 August).

Computer people and molecular biologists talk to each other on several different levels. There is, for example, the housekeeping of molecular biology - the management of databases such as those accumulating the nucleotide sequences of genes and even genomes, the amino-acid sequences of protein molecules and the atomic coordinates of the macromolecules determined by $\mathrm{X}$-ray and other techniques. But computers are increasingly one of the means by which problems in molecular biology may be solved, perhaps by the intelligent display of information (as with molecular models) or the discovery of the structure of a molecule by molecular dynamics or some other technique. But the ambitious among the computer people look further ahead, to the point at which hardware, perhaps in the form of neural networks or some other embodiment of artificial intelligence, will answer and perhaps even ask questions of a more generally conceptual character.

What follows is not a formal report of this stimulating occasion, but an impression of it. And the outstanding ingredient of that must be the way in which the basement room given over to the workstations used to demonstrate the software people had brought with them to the party seemed always to be crowded with inquisitive potential users. Interestingly, the bulk of those with soft- ware to show off are people with a background in biology, but there were also refugees from fields such as astrophysics where, for one reason or another, financial support is hard to come by. One purist of a computer scientist used the word "amateurs", but softly.

The amateurs, however, have a down-toearth appreciation of what their potential users need. Making genetic maps available on notebook computers typifies a common assumption that the user molecular biologist will not be separated from his or her data for any length of time. The general willingness to let others have copies of interesting software is impressive. So is the generality of the ambition that the better projects will be taken up by professional software houses. Indeed, that rather than what potential users say, seems to be the touchstone of quality.

But many of them also share a vague sense of disappointment that most of the users are still asking relatively unsophisticated questions of the data accumulating in the databanks. Searching through a genome, or the parts of it already stored as data, for the occurrence of a predetermined nucleotide sequence, is easy enough, even if it takes a little time. But at least one computer buff looks forward to software designed to annotate the nucleotide sequences submitted to the databanks which will deliver to the author of the data a comprehensive statement of their biological interest.

But is not most of any genome junk, in any case? Sydney Brenner, putting the case for the study of the genome of the Japanese puffer-fish as the most compact vertebrate genome and thus that best suited as an intermediate between those of the nematode and the human being, took it for granted that most of the junk is without meaning. But some of the arresting work described at the meeting showed that regulatory sequences for specific genes may be found tens of thousands of kilobases from the genes whose activity they regulate, not only upstream of them but also downstream. But if at least some genes are not much larger than the sequences that specify the structure of the proteins transcribed from them, the prospects for the automatic readout by machine of the properties of a genetic sequence are evidently diminished. In other words, molecular biologists would be asking more sophisticated questions if their field were not at such an early stage in its development.

So much is also clear from the famous protein-folding problem, on which a substantial subset of the computer people have lavished effort. The most effective compu- ter-aided folding on show here has been that in which the unknown structure of a protein is guided by the homology there may be between its sequence of amino acids and that of a protein whose structure is stored in one of the databases. De novo folding by machine remains an uncertain business.

Luckily, there seems to have been more confident progress in the use of packages of molecular interactions, and of the very substantial computing engines, to predict the structures of RNA molecules specified simply by their sequences. But in both cases, the interactions of the specified molecules with their mostly aqueous surroundings is accounted for by supposing the exterior to be homogenous. Could it be for that reason that the computers have so far had so little to say about the functioning of macromolecules with relatively specific functions, as enzymes or as ribozymes?

Issues concerning RNA kept cropping up at the meeting, notably because of enthusiasm for the notion that random assemblages of RNA molecules may have been the entities from which life emerged. Indeed, Stuart Kauffman from the Sante Fe Institute provided an account of how, by arranging to assemble a random collection of building blocks of macromolecules "in a pot", it should be possible to make and identify novel biological chemicals. But that was bettered by an account of an experiment at the Massachusetts General Hospital in which a collection of random RNA molecules has been induced, under external selection pressure, to evolve a more effective ligase than that possessed by the cells from which the random molecules were derived.

These, of course, are the hints at how life may have begun that send the computer people rushing to their notepads. Although it appears that there is already a computer game on the toy market that simulates evolution, the interest in building really sophisticated models is powerful, and unlikely to be subdued by uncertainties about the parameters. The difficulty of modelling the mix of carbon compounds recognized by radioastronomers in interstellar space may be a more salutary lesson.

Meanwhile, there seems no doubt that the marriage Temple Smith effected with some difficulty six years ago has come to stay. It is not just that each partner recognizes the need of the other, but that each also sees opportunities that could not be accomplished in isolation. It is an easy guess that the fourth workshop will be even more instructive.

John Maddox 